\title{
What is the heritable component of spinal deformities in the European sea bass (Dicentrarchus labrax)?
}

\author{
Agnès Bardon ${ }^{a}$, Marc Vandeputte ${ }^{a, b},{ }^{*}$, Mathilde Dupont-Nivet ${ }^{b}$, Hervé Chavanne ${ }^{c}$, Pierrick \\ Haffray $^{\mathrm{d}}$, Alain Vergnet ${ }^{\mathrm{a}}$ and Béatrice Chatain ${ }^{\mathrm{a}}$
}

\footnotetext{
a Ifremer, Chemin de Maguelone, F-34250 Palavas-Les-Flots, France

b INRA, UMR 1313 Génétique Animale et Biologie Intégrative, F-78350 Jouy-en-Josas, France

' Panittica Pugliese, Torre Canne di Fasano, Italy

d Sysaaf, Section aquacole, Station SCRIBE, Campus de Beaulieu, F-35042 Rennes, France
}

*: Corresponding author : Marc Vandeputte, Tel.: +33 4 67130407; fax: +33 4 67130458, email address : Marc.Vandeputte@jouy.inra.fr

\begin{abstract}
:
Malformations in farmed fish are a prime research topic as it has a major impact on fish welfare and on the economical value of the product. In this study, the genetic component of spine deformities was estimated in European sea bass, a major species of Mediterranean aquaculture, with the use of a posteriori reconstruction of pedigree with microsatellites. Our population exhibited a very high malformation rate (81\%), probably due to intense swimming of fish during pre-growing. The heritability of global spine deformities was evaluated to be $0.21 \pm 0.04$ on the underlying scale $(0.33 \pm 0.06$ for lordosis, $0.13 \pm 0.04$ for scoliosis). Deformities scored by an internal or external examination turned out to be genetically the same trait (genetic correlations $>0.9$ ), although phenotypic correlations were moderate to high $(0.45 \pm 0.04$ to $0.92 \pm 0.01)$ due to difficulties in scoring the less severe deformities. Along time (from 100 to $800 \mathrm{~g}$ mean weight), lordosis had a constant heritability, with very high genetic correlations between stages (>0.9). Its incidence increased from 39 to $53 \%$ indicating that the malformation was probably present from the beginning of the rearing period but that its expression increased over time. A positive linkage between spine deformities and growth rate was demonstrated both by the higher early weight of affected fish and by the positive genetic correlation between weight and malformation (from $0.21 \pm 0.15$ to $0.40 \pm 0.14$ ), although deformities have a negative phenotypic impact on growth. However, heritabilities of malformation traits calculated here are only estimates that may indirectly describe the sensitivity of fish to the particular pre-growing environment as a function of different body weight genotypes. A quantification of realised heritability would therefore be necessary before concluding on the existence of a genetic basis for spinal malformations such as lordosis and scoliosis. Nevertheless and by precaution, selection for fast growth rate needs careful monitoring of deformities, and selection against malformations may counteract impacts of selection for fast growth.
\end{abstract}

Keywords: European sea bass; Dicentrarchus labrax; Deformities; Growth; Heritability; Genetic correlations 


\section{Introduction}

The study of malformations in farmed fish is a research topic of a prime importance for the aquaculture sector. It has received an increasing attention over the last 20 years, and progress has been made towards causative factors and improved rearing procedures. The problem nevertheless persists, and remains significant for the industry as it reduces the marketing value of fish throughout the value chain of almost all aquaculture species. These anomalies also have important implications on the sustainable development of aquaculture, consumer perception, and animal welfare (Komen et al., 2002). Important external deformities negatively impact the product image, and fish with small deformities that may externally look normal, also represent a great problem for the hatcheries that sell their fry X-rayed to attest their quality. Additionally, it may cause technical problems to automated filleting equipment (Gjerde et al., 2005). Deformed fish increase production costs, as they require manual sorting, and lower performances (i.e. swimming ability, conversion index, growth rate, survival, and susceptibility to stress, pathogens and bacteria; Boglione et al., 2001).

Fish species may develop different types of abnormalities that have been widely described (Andrades et al., 1996; Divanach et al., 1996; Afonso et al., 2000; Gavaia et al., 2002; Fraser et al., 2004; Kranenbarg et al., 2005a; Boglione et al., 2006; Fjelldal et al., 2007). The most cited are malformations of the spine comprising lordosis ( $V$-shaped curvature in the sagittal plan), scoliosis (lateral curvature), and sometimes a combination of both. In the European sea bass (Dicentrarchus labrax), most of the malformations occur during the larval period and average 10\% in most batches, while without any reason presently understood, some batches may reach 80 to $100 \%$ deformed fish.

Several physiological, environmental, xenobiotic, nutritional and genetic factors have been linked to this problem during larval and juvenile development stages of cultured freshwater and marine fish (Divanach et al., 1996; Boglione et al., 2001; Gorman and Breden, 2007), e.g.:

Hypoxia during somitogenesis (Sawada et al., 2006a, b),

Brutal variations of temperature during incubation or larval rearing (Abdel et al., 2004; Sfakianakis et al., 2004; Georgakopoulous et al., 2007),

Abnormal swimbladder development causing spinal curvature affecting vertebrae located behind the digestive mass and aggravated by muscle pressure during forced swimming (Chatain, 1994a; Divanach et al., 1997; Kihara et al., 2002; Kranenbarg et al., 2005b; Sfakianakis et al., 2006).

Dysfunctions in osteogenesis due to inadequate amounts or interactions of diverse nutritional components such as calcium, phosphorus, vitamins A, C, D, E and K (Beaverfjord et al., 1998; Madsen and Dalsgaard, 1999; Oliva-Teles and Pimentel-Rodrigues, 2004; Sugiura et al., 2004; Villeneuve et al., 2006; Cahu et al., 2003; Lall and Lewis McCrea, 2007). The physiological process involved in the normal bone development in fish was only recently investigated, but the recently demonstrated mineralization rearrangement during growing indicates its complexity (Deschamps et al., 2008).

Genetics is usually considered marginal although it appears to be significant in several cases. For example, the level of morphological aberrations of pectoral fins that varied between 0 to $75 \%$ in crosses of two strains of African catfish (Clarias gariepinus and Heterobranchus longifilis) indicated the involvement of the genotype rather than the influence of environment (Aluko et al., 2001). The heritability of fin deformities was also shown to be significant but low $(0.09 \pm 0.04$, estimated by animal model on the observed scale) in the common carp (Cyprinus carpio, Kocour et al., 2006). In Atlantic salmon (Salmo salar), the susceptibility to a specific spinal deformity was estimated heritable $(0.25$ and 0.14 , based respectively on the sire and dam component of variance, McKay and Gjerde, 1986), and the vertebral deformity was shown to be determined by a substantial additive genetic component (from $0.00 \pm 0.00$ to $0.20 \pm 0.08$ on the observed scale in the four year-classes of Atlantic salmon; Gjerde et al., 2005). Moreover, genetic correlations established between deformed skeletal structures, recorded in different cohorts of salmonids and 
rearing environments, showed that improved management conditions could decrease the deformity incidence, and that the genetic architecture of the "deformity" trait depends on the environment and on the incidence of deformities (Kause et al., 2007). On the other side, no evidence of genetic component for skeleton abnormality has been found in the gilthead sea bream (Castro et al., 2008). In the European sea bass, a major species for Mediterranean aquaculture, the genetic component of spine deformities was never evaluated.

One of the most important constraints for estimating genetic parameters in fish is the inability to tag hatchlings, and consequently the need to separately rear the families until tagging size, which may bias or reduce the precision of the estimated parameters. In the present study, we used an interesting alternative to separate rearing of families, which is the use of mixed rearing of progenies with a posteriori reconstruction of pedigrees using highly variable markers such as microsatellites. The major benefits of this methodology are the absence of between-family environmental effects, the possibility to work in industry conditions with good experimental power, and to use highly informative factorial designs (Vandeputte et al., 2001). In the present experiment, we took advantage of the high incidence of inadvertent spine deformities in a large set of mixed families of sea bass to examine the genetic component of spine deformities. Internal deformities were visually evaluated on filleted fish about $800 \mathrm{~g}$ mean weight, and related to external records at this stage. The evolution over time of externally recorded deformities was also tracked, thanks to the fact that fish were individually tagged and photographed at different ages. These data were used to study the genetic variation of deformities and its interactions with growth traits.

\section{Materials and methods}

\subsection{Animals}

Selection of breeders, reproduction process and larval rearing were previously described in details in Dupont-Nivet et al. (2008). Briefly, the parents of the studied animals were wild sea bass of Atlantic origin collected by Panittica Pugliese S.A. (Torre Canne di Fasano, Italy) on the Northern coast of Brittany (France). Reproduction of these fish was performed in this farm, i.e.: an expected 253 full-sib families issued from 33 sires and 23 dams produced according to a partly factorial mating design in three sets of 11 sires mated with 9, 7, and 7 dams respectively. Within each set, a full factorial crossing was accomplished. Sperm was cryopreserved (Fauvel et al., 1998) and eggs were obtained by manual stripping following hormonal induction of ovulation. For all parents a fin clip was collected and kept in $90 \%$ ethanol for DNA analyses and later parentage assignment. All fish were reared in the same tank until the age of 134 day-old post hatching (D134; $3.6 \mathrm{~g}$ ), then a random sample of 16,000 fish was sent to the Ifremer station in Palavas (France) to be pregrown in a $5 \mathrm{~m}^{3}$ tank in a recirculated system. At D156, the batch was split at random into four $5 \mathrm{~m}^{3}$ tanks to lower the density. These tanks are referred to as "initial tanks" in the further statistical analyses. At D370 (35 g), 1753 fish were randomly selected from these tanks, individually PIT-tagged, fin-clipped (kept in 90\% ethanol for further DNA analyses so as the parent were) and gathered in a unique tank of the same circuit. The rearing density then was maintained below $30 \mathrm{~kg} / \mathrm{m}^{3}$, and the temperature between $20-22{ }^{\circ} \mathrm{C}$ during the whole rest of the experiment. At three occasions, because fish density reached 33 to $35 \mathrm{~kg} / \mathrm{m}^{3}$, each batch was randomly split in two: at D504, from one tank to two, at D594 from two tanks to four and at D714 from four tanks to eight. These eight tanks are referred to as "final tanks" in the further statistical analyses. 


\subsection{Data collection}

The fish were anaesthetized $(0.3 \mathrm{ml} / /$ phenoxy-2-ethanol), and their weight and length individually recorded at D370 (mean weight $36 \mathrm{~g}$ ), D504 (101 g), D714 (398 g), and D986 (824 g). To simplify the writing, these stages are referred as stage $35 \mathrm{~g}, 100 \mathrm{~g}, 400 \mathrm{~g}$ and $800 \mathrm{~g}$, respectively. Each fish was photographed at the stages 100,400 and $800 \mathrm{~g}$. At this last record the surviving fish $(\underline{n}=1,466)$ were killed, their sex was determined by visual examination of the gonads, and their internal deformities were recorded by the observation of the spine after removal of the left fillet. Spine deformities that could be seen externally were also visually recorded on the photographs according to individual shape characteristics. Only 1,328 fish were kept for the analysis that responded to the following criteria: (i) their photographs could be exploited at the three stages 100,400 and $800 \mathrm{~g}$, (ii) they were checked for internal deformities at $800 \mathrm{~g}$ and (iii) they were correctly assigned to a single parental pair. Two types of deformities were assessed, i.e.: lordosis (L) when spinal column had a V-shaped curvature in the sagittal plan, and scoliosis (S) when it presented an abnormal lateral curvature. Each deformity was coded e (external score) or i (internal score at stage $800 \mathrm{~g}$ ), and deformed or normal fish scored one or zero, respectively. Whatever the type of malformation, all deformed fish were pooled to create the trait referred to as malformation $(\mathrm{M})$ while the non-affected fish were scored as normal $(\mathrm{N})$.

\subsection{Parentage assignment}

Parentage assignment was performed by Landcatch Natural Selection (Alloa, Scotland) using six microsatellite markers organised in a single PCR multiplex. Parentage allocation was performed using a proprietary software for pedigree analysis. The software used two separate algorithms for pedigree assignment: a Bayesian probabilistic calculation computed the most likely parents; and a simple text matching algorithm compared parental and offspring genotypes at each locus sequentially, and excluded mismatches in turn. The two sets of results were then compared. There was almost perfect concordance between the two sets of assignments. Out of the 1,753 genotyped fish, 1,743 (99.4\%) could be assigned to a single parental pair, of which 1,328 had complete data (see before). The number of fish per family is given in Table 1.

\subsection{Statistical analyses}

The individual deformity scores ( 0 or 1 for each deformity trait) were first analysed by logistic regression based on a factorial design, using $S A S \circledR$ Logistic procedure to determine the potential significant fixed effects.

For the heritability calculation, malformation was considered as a threshold trait, and was first analysed on the observed scale $(0=\mathrm{N}, 1=\mathrm{M})$ for all data using VCE5.1.2 software (Kovac and Groeneveld, 2003), with an univariate animal model:

$Y=X \beta+Z a+\varepsilon$

[Model 1]

where $\underline{Y}$ is the vector of observations, $\underline{\beta}$ is the vector of fixed effects (overall mean, sex, initial and final tank), $\underline{a}$ is the vector of random additive genetic effects and $\underline{\varepsilon}$ the vector of random residual effects. $\underline{X}$ and $\underline{Z}$ are known incidence matrices. Initial tank fixed effects were used to model deformities at all stages, while final tank effects were used only for deformities at stage $800 \mathrm{~g}$. Maternal effect was not significant for the malformations and therefore was not included in this model. Then, heritabilities estimates were transformed to the underlying liability scale using the Dempster and Lerner correction (Dempster and Lerner, 1950), which has been shown to yield unbiased estimates of heritability on the underlying scale in most cases (Mantysaari et al., 1991). Additionally, restricted maximum likelihood estimates of variance components for animal additive genetic and error effects were obtained directly on the underlying liability scale (LOGIT modelling) using the ASREML software (Gilmour et al., 2002). In this case, a sire and dam model with the same fixed effects was used, and heritability was estimated from the sire component of variance using the formulae from Becker (1984). The error variance for the LOGIT model was the variance of the logit link function, (3.29 or $\pi^{2 / 3}$ ). 
Genetic correlations between malformations were estimated with the model 1 from bivariate analyses, using the VCE5.1.2 software (Kovac and Groeneveld, 2003). Analyses were made first between internal and external malformations recorded at D986, then between types of deformities (lordosis, scoliosis and malformation) at each stage, and finally between the different stages to precise the evolution of lordosis over time. The observed scale was used to estimate the genetic correlations because genetic correlations between binary traits have been shown to be equal on the observed and on the underlying scale (Gianola, 1982), and because genetic correlations between one binary trait on the observed scale and a normally distributed trait are very similar to the true correlations as long as the threshold trait does not have both low heritability and low incidence (Olausson and Ronningen, 1975; Mercer and Hill, 1984). Phenotypic correlations between deformity traits were calculated as tetrachoric correlations, and their standard errors evaluated with SAS-FREQ.

A general linear model (SAS ${ }^{\circ}$ GLM) was used to estimates least squares means of weight and length in deformed and normal fish. In this model, the malformation effect (lordosis, scoliosis and malformation) was considered as a fixed effect, as well as sex, initial tank and final tank. Sire and dam effects were included as random effects. The least squares means were compared with a Tukey-Kramer test when the malformation effect was significant.

To estimate the genetic correlations between malformations and growth-related traits (weight and length), we used a bivariate animal model, including a non-genetic maternal random effect for the modelling of growth traits:

$Y=X \beta+Z_{1} a+Z_{2} m+\varepsilon$

[Model 2]

where $\underline{Y}$ is the vector of observations (malformation and weight or length), $\underline{\beta}$ is the vector of fixed effects (overall mean, sex, initial tank and final tank at stage $800 \mathrm{~g}$ ), $\underline{a}$ is the vector of random additive genetic effects, $\underline{m}$ is the vector of random non-genetic maternal effects and $\underline{\varepsilon}$ the vector of random residual effects. $\underline{X}, \underline{Z}_{1}$ and $\underline{Z}_{2}$ are known incidence matrices. Maternal random effects were applied to the modelling of growth traits (but not malformation traits), as they were shown to have an impact on the additive variance of growth traits in this experiment (Dupont-Nivet et al., 2008). A fixed effect of malformation was included for the modelling of growth traits to take into account the phenotypic impact of malformations on growth.

\section{Results}

\subsection{Incidence of deformities and significance of effects}

In the fish population studied, the global incidence of malformations was high ( $>40 \%$, Table 2$)$. The incidence of internal spine deformities at stage $800 \mathrm{~g}$ attained $81 \%$ (Mi), the proportion of Iordosis ( $\mathrm{Li}$ ) and scoliosis (Si) respectively $48 \%$ and $73 \%$, and $40 \%$ of the fish suffered both from lordosis and scoliosis. The rate of external deformities increased with age (e.g. from 41 to $65 \%$ for $\mathrm{Me})$, lordosis being the main deformity scored in this way $(>75 \%$ of the observed external deformities at all stages). External scoliosis had a very low incidence level at stages $100 \mathrm{~g} \mathrm{(5 \% )}$ and $400 \mathrm{~g} \mathrm{(8 \% )}$ but soared to $31 \%$ at stage $800 \mathrm{~g}$, even if such external determination largely underestimated the real incidence of scoliosis at this stage.

At slaughter (stage $800 \mathrm{~g}$ ) incidence of internal and external deformities could be compared. If we refer to the internal deformity globally, among the $81 \%$ fish being internally deformed (Table 2), only $77 \%$ were externally spotted; on the contrary, among the $19 \%$ internally normal fish, $15 \%$ were scored wrongly as externally deformed. If we refer to the internal deformity type by type, among the $48 \%$ and $73 \%$ of fish respectively scored with at least one internal lordosis or scoliosis, $91 \%$ and $37 \%$ were adequately identified externally as lordotic or scoliotic, respectively. 


\subsection{Heritabilities and correlations between deformities}

According to the $S A S \otimes$ logistic procedure, sex influenced malformations except on internal scoring, and only when their incidence was higher than $10 \%(\underline{P}<0.05$, Table 2$)$. The initial tank effect affected significantly all deformity types at stage $100 \mathrm{~g}(\underline{P}<0.05)$. This factor had no effect on scoliosis at stages 400 and $800 \mathrm{~g}$ (external and internal records), or on external malformation trait at stage $800 \mathrm{~g}$. The final tank effect was significantly linked to external deformities at slaughter and to internal lordosis $(\underline{P}<0.05)$.

As expected, heritability estimates on the liability scale following the Dempster and Lerner correction $\left(\mathrm{h}_{\mathrm{u}}{ }_{\mathrm{u}}\right)$ were higher than heritabilities on the observed scale $\left(\mathrm{h}^{2}\right)$. Heritabilities estimated directly on the liability scale with the sire component of variance from ASREML $\left(\mathrm{h}^{2}\right.$ ASReml $)$ were quite close to the estimates obtained with the Dempster and Lerner corrections, although generally lower. Heritability estimates on the liability scale $\left(\mathrm{h}^{2} \mathrm{u}\right)$ had lower standard errors than $\mathrm{h}^{2}$ ASReml, which could be expected as they were from an animal model, therefore taking into account the whole additive genetic relationship matrix instead of only the variation between sires. Therefore, only heritability estimates on the liability scale $\left(\mathrm{h}^{2} \mathrm{u}\right)$ will be considered in the rest of the paper. They were low to moderate for the different traits, ranging from $0.13 \pm 0.04$ to $0.33 \pm 0.06$. For internal deformities recorded at stage $800 \mathrm{~g}$, heritability estimates were $0.21 \pm 0.04$ for the malformation trait, and $0.33 \pm 0.06$ and $0.13 \pm 0.04$ for lordosis and scoliosis, respectively.

The heritability estimates for the internal and external malformation trait were almost the same $(0.21 \pm 0.04$ and $0.25 \pm 0.05$ respectively, Table 3$)$, and the genetic correlation between both was very high $(0.96 \pm 0.04)$ while the phenotypic correlation was moderately high $(0.79 \pm 0.03)$ probably due to external scoring errors.

The heritabilities for internal and external lordosis were also similar $(0.33 \pm 0.06$ and $0.27 \pm 0.05$ respectively), and the genetic correlation between them was very close to $1(0.99 \pm 0.01)$ with a high phenotypic correlation $(0.92 \pm 0.01)$. Finally, although similar, the heritability estimates of internal and external scoliosis were lower than for the other deformities $(0.13 \pm 0.04$ and $0.19 \pm 0.05$ respectively) so as the value of their genetic correlation, even if it still remained high $(0.90 \pm 0.10)$. The phenotypic correlation between these both traits was low $(0.19 \pm 0.04)$, the limited reliability of external scored scoliosis being explained by the fact that only $37 \%$ of internal scoliosis were externally visible.

To precisely estimate the link between the different types of deformities, only internal malformations were compared to limit the bias induced by scoring errors. The moderately high genetic correlation $(0.69 \pm 0.10)$, and the low phenotypic correlation $(0.39 \pm 0.04)$ between lordosis and scoliosis could indicate they only had a partial common genetic basis, and perhaps different patterns of expression.

\subsection{Evolution of malformations over time}

Because scoliosis were difficult to evaluate externally and the malformation trait was a combination of all deformities, the most precise trait to study the malformations evolution over time was the lordosis. Its heritabilitiy was around 0.30 at all stages (Table 4), and genetic correlations between measurements were high $(0.92 \pm 0.03$ to $0.99 \pm 0.01)$, meaning that lordosis evaluated from stage $100 \mathrm{~g}$ had the same genetic basis than as those evaluated at stage $800 \mathrm{~g}$, although the incidence was different (39\% vs. $53 \%)$. On the contrary, phenotypic correlations slightly decreased over time from $0.93 \pm 0.01$ to $0.83 \pm 0.02$, probably due to this variation in incidence. 


\subsection{Deformities and growth}

Least square means of weight and length at the different stages are given in Table 5, for fish affected or not by an internal malformation (global malformation, lordosis or scoliosis). Deformed fish were significantly heavier at stages 35 and $100 \mathrm{~g}$ but shorter at stages 400 and $800 \mathrm{~g}$. Those affected by lordosis were shorter at all stages and lighter at stages 400 and $800 \mathrm{~g}$. Those affected by scoliosis were heavier and longer at stages 35 and $100 \mathrm{~g}$ but shorter at stages 400 and $800 \mathrm{~g}$.

The genetic correlations between weight, length and the different types of deformities are shown in Table 6. Malformation trait and scoliosis were positively correlated with weight $(0.30 \pm 0.15$ and $0.41 \pm 0.19$ on average, respectively), but less with length ( $0.17 \pm 0.15$ and $0.28 \pm 0.19$, respectively). On the contrary, lordosis was weakly but negatively correlated with weight and length, and more related to length than weight $(-0.11 \pm 0.11$ and $-0.28 \pm 0.13$, respectively). Globally, the standard errors were relatively high (around 0.15), meaning that the genetic correlations were not different from zero in many cases. The only significant ones were positive correlations between weight and malformations at 100 and $400 \mathrm{~g}$, between weight and scoliosis at 35 and $800 \mathrm{~g}$ and negative correlations between length and lordosis at $800 \mathrm{~g}$.

\section{Discussion}

\subsection{Incidence and heritability}

First of all, it is important to point out that our experimental population was unusual as its exhibits a very high malformation rate (81\%). According to Kause et al. (2007) such a high incidence would suggest that deformities were induced by of a single major stressor. Indeed, we sensed that the likeliest cause lied in the hydrodynamics conditions the post-larvae were subjected to during pre-growing, i.e.: the juveniles were maintained, from $3.6 \mathrm{~g}$ to the end of the experiment, in $5 \mathrm{~m}^{3}$ circular tanks the main characteristic of which is the self-cleaning by a circular water current. Besides, it is known that intense swimming provoked by such a water current is not suitable for juveniles that have not completed their bone calcification, because fast swimming increases muscle mechanical constraints on vertebrae (Chatain, 1994b). This hypothesis would be supported by the fact that another batch of same fish kept in "soft swimming" conditions in a raceway did not suffer from such deformities, and does not exclude that hydrodynamics might only reveal the fish sensitivity to spinal deformities, the skeletal development remaining under genetic control (Wagner and Karsenty, 2001).

The first finding of this study was that the spine deformities in the European sea bass could have a heritable component. The heritability of the internal malformation trait was indeed estimated to be $0.21 \pm 0.04$ on the underlying scale using Dempster and Lerner correction, which is the range of heritability estimates for vertebral deformity found in other species, i.e.: 0 to $0.36 \pm 0.14$ in the fouryear classes of farmed Atlantic salmon Salmo salar (Gjerde et al., 2005), 0.64 for the same species estimated on the liability scale based on the sire component of variance (McKay and Gjerde, 1986), and 0.27 in Atlantic cod, Gadus morhua using a mixed linear animal model (Kolstad et al., 2006a).

\subsection{Correlations between malformations}

The correspondence between internal and external malformations is clearly established here according to the high genetic correlations found $(>0.90)$. The heritability estimates are almost the same for all malformations, and the phenotypic correlations are relatively high $(0.77 \pm 0.03$ $0.92 \pm 0.01$ ) with an exception for scoliosis $(<0.54 \pm 0.04)$. Indeed, the difference between internal lordosis and scoliosis was expressed by a low phenotypic correlation $(0.39 \pm 0.04)$, and a moderate 
genetic correlation $(0.69 \pm 0.10)$. Scoliosis seems to be less heritable than lordosis, and fish may have a differential genetic sensitivity to lordosis and scoliosis whereas the malformation trait can be approached like a standard measure of both lordosis and scoliosis. Even though Afonso et al. (2000) suggested that a triple column abnormality in sea bream consisting of a consecutive repetition of lordosis-scoliosis-kyphosis (LSK) from head to tail, had polygenic origin, here, scoliosis and lordosis, although significantly linked, cannot be considered strictly as the same trait.

This study also points out that, in sea bass, external recording of malformations underestimates the true deformity rate, as less severe deformities like scoliosis may remain unseen. This was already shown in other species, for example, in Atlantic cod, the proportion of malformations determined by visual examination of shape, varied from 28 to $74 \%$ according to rearing sites (Kolstad et al., 2006b). In the Atlantic salmon, Fjelldal et al. (2007) found a prevalence of vertebral deformities of $12.4 \%$ when evaluated on radiographs, and $1.3 \%$ when externally recorded. On the same species, Witten et al. (2006) and McKay and Gjerde (1986) found prevalences of vertebral deformities of $12 \%$ both on radiological and/or external examinations, but in the four-year classes, malformations rates varying between 1.5 to $25.2 \%$ when estimated by external examinations (Gjerde et al., 2005). The low phenotypic correlation between external and internal scoliosis found in this study confirms the difficulty to distinguish by external examination animals suffering from scoliosis. Therefore, the validity of heritability and genetic correlations for the "external scoliosis" trait in the present experiment should be taken with caution. In the framework of a breeding programme, external recording of deformities would therefore be relevant in a family-based scheme, as it would allow effective ranking of families thanks to the high genetic correlation between external deformities and the "real" (internal) deformity trait. However, in the case of individual selection, this might not be as effective, especially for detecting scoliosis, the X-ray remaining the only method to clearly perceive them without killing the fish.

\subsection{Evolution of malformations over time}

Even if the severity of deformities may increase with age and the early visual evaluation may be more difficult than at a late stage, the homogenous heritabilities estimated at the different stages for lordosis indicate that the deformity was present from the beginning of rearing period, but not pronounced enough to be externally detected. This is supported by the high genetic correlations between deformities at different stages $(>0.92 \pm 0.03)$. Indeed, the number of deformed fish progressively increased in each class of malformation and no fish classified as deformed precociously became normal later. This observation supports the hypothesis that prematurely deformed fish remained deformed and that normal fish could become deformed. The ontogenesis of deformities can then be explained by both genetic and environmental factors, the prevalence of the later depending of its intensity and the development stages during which it impacts.

\subsection{Malformation and growth}

The fish that were affected by scoliosis at slaughter were found equivalent in weight and length to those that did not present such a deformity. They were nevertheless shown to have been larger (both length and weight) than non-affected fish at 35 and $100 \mathrm{~g}$. For lordosis and malformation trait, the picture was less clear. However, it is highly unlikely that spine deformities could have a positive impact on growth, as they mechanically shorten the fish, and probably reduce their access to food by preventing correct swimming as suggested in different species where malformation often related to reduce growth rate (McKay and Gjerde, 1986; Kause et al., 2005, Kocour et al., 2006). Still, fast growth was also recognized to be a risk factor for spinal malformations (Rauw et al., 1998) a phenomenon that fits well to our study, and that would occur as follows: shortly after the onset of malformations, more deformities would affect fast-growing fish but with little effect, then as the fish grow, their deformities progressively aggravate (as described in salmon; Witten et al., 2006), and have a negative impact on growth. This would be confirmed by the positive genetic correlation found between scoliosis or malformation and weight at the different ages, even though the standard errors are large, and these estimates have to be taken cautiously, 
as the only significant correlations were with weight and malformations at 100 and $400 \mathrm{~g}$, and with weight and scoliosis at 35 and $800 \mathrm{~g}$. It would also confirm previously suspected links between fast growth rate and sensitivity to spine deformities in cod (Kolstad et al., 2006a), and sea bass (Vandeputte et al., 2009). Furthermore, the fish used for this analysis have grown in particular conditions, which are known to induce spinal deformities, here at a very high incidence. At high levels of deformity rate, families may show different but consistent sensitivities to the stressor, leading to high genetic variation and moderate heritability, while the genetic architecture depends on the existing expression of trait and deformities at different generations may not share common genetic determination (Kause et al., 2007).

However, heritabilities of malformation traits calculated here are only estimates that may indirectly describe a sensitivity to the particular pre-growing environment endured by fish characterised by different body weight. Indeed, if the occurrence of malformations in a batch depends on a limiting factor affecting the body weight at a certain age, then big or small fish would be differently affected by the malformation according to their weight. This would be supported by the highest genetic correlation with growth observed at the younger ages, and by the instability of the genetic basis of such type of traits according to year-classes (Gjerde et al., 2005; Kause et al., 2007). It would be strongly recommended to proceed to the quantification of realised heritability before concluding to the existence of a genetic basis of spinal malformations such as lordosis and/or scoliosis.

Nevertheless, as in this study, the heritability of malformations was significant, it can be safely recommended, by precaution, to eliminate deformed fish from a breeding nucleus. However, this trait has to be monitored carefully in breeding programmes directed to fast growth because eliminating deformed fish while major risks of malformations are suspected to lie on early fast growing individuals, might not permit to fully exploit the genetic potential for growth. In another experiment, selection for growth in sea bass did not result in a higher percentage of deformed fish in the offspring of selected males (Vandeputte et al., 2009). However, the fact that deformed males were removed from the selection process in this latter experiment could alter the results.

Finally, to clearly demonstrate the genetic basis of such malformations, we would recommend to proceed to intentional crossing between malformed fish to evaluate their effective predisposition to produce malformed progenies. Moreover, because environmental variations were clearly shown to impact the expression of deformities (Kause et al., 2007; Kolstad et al., 2006b; Witten et al., 2006), the future experiments should also include the determination of the interactions between environment and malformations.

\section{Acknowledgements}

This work was carried out in the framework of a CRAFT project no. Q5CR-2002-71720 (Heritabolum) funded by the EC and the private farms Panittica Pugliese (Italy), Viveiro Villanova (Portugal) and Ardag (Israel), which are also thanked for their active participation. The present work was also part of the program of the Research Group 'Fish Genetic Improvement' between INRA and Ifremer.

\section{References}

Abdel, I., Abdellan, E., Lopez-Albors, O., Valdes, P., Nortes, M.J., Garcia-Alcazar, A., 2004. Abnormalities in the juvenile stage of sea bass (Dicentrarchus labrax L.) reared at different temperatures: types, prevalence and effect on growth. Aquacult. Internat. 12, 523-538.

Afonso, J.M., Montero, D., Robaina, L., Astorga, N., Izquierdo, M.S., Gines, R., 2000. Association of a lordosis-scoliosis-kyphosis deformity in gilthead seabream (Sparus aurata) with family structure. Fish Physiol. Biochem. 22, 159-163. 
Aluko, P. O., Awopetu, J.I., Adeola, A.O., 2001. Genetic basis of pectoral fin deformities in the African catfish Clarias gariepinus (Burchell 1822), Heterobranchus longifilis (Valenciennes 1840) and their hybrids. Aquacult. Res. 32, 21-27.

Andrades, J.A., Becerra, J., Fernandez-Llebrez, P., 1996. Skeletal deformities in larval, juvenile and adult stages of cultured gilthead sea bream (Sparus auratas L.). Aquaculture 141, 1-11.

Beaverfjord, G., Asgard, T., 1998. Development and detection of phosphorus deficiency in Atlantic salmon, Salmo salar L., parr and post-smolts. Aquacult. Nut. 4, 1-11.

Becker, W.A., 1984. Manual of quantitative genetics. academic enterprises. Pullman, Washington, $188 \mathrm{pp}$.

Boglione, C., Gagliardi, F., Scardi, M., Cataudella, S., 2001. Skeletal descriptors and quality assessment in larvae and post-larvae of wild-caught and hatchery-reared gilthead sea bream (Sparus aurata L. 1758). Aquaculture 192, 1-22.

Boglione, C., Costa, C., Giganti, M., Cecchetti., M., Di Dato, P., Scardi, M., Cataudella, S., 2006. Biological monitoring of wild thicklip grey mullet (Chelon labrosus), golden grey mullet (Liza aurata), thinlip mullet (Liza ramada) and flathead mullet (Mugil cephalus) (Pisces: Mugilidae) from different Adriatic sites: meristic counts and skeletal anomalies. Ecol. Indicators 6, 712-732.

Cahu, C., Zambonino-Infante, J.L., Takeuchi, T., 2003. Nutritional components affecting skeletal development in fish larvae. Aquaculture 227, 245-258.

Castro, J., Pino-Querido, A., Hermida, M., Chavarrias, D., Romero, R., Garcia-Cortes, L.A., Toro, M.A., Martinez, P., 2008. Heritability of skeleton abnormalities (lordosis, lack of operculum) in gilthead seabream (Sparus aurata) supported by microsatellite family data. Aquaculture 279, 1822.

Chatain, B., 1994a. Abnormal swimbladder development and lordosis in sea bass (Dicentrarchus labrax) and sea bream (Sparus auratus). Aquaculture 119: 371-379.

Chatain, B., 1994b. Estimation et amélioration des performances zootechniques de l'élevage larvaire de Dicentrarchus labrax et de Sparus auratus. Doctorat d'état, Université d'Aix-Marseille II, 199 pp.

Dempster, E.R., Lerner, I.M., 1950. Heritability of threshold characters. Genetics 35, 212-236.

Deschamps, M.H., Kacem, A., Ventura, R., Courty, G., Haffray, P., Meunier, F.J., Sire, J.-Y., 2008. Assessment of "discreet" vertebral abnormalities, bone mineralization and bone compactness in farmed rainbow trout. Aquaculture, 279, 11-17.

Divanach, P., Boglione, C., Menu, M., Kounoundouros, G., Kentouri, M., Cataudella, S., 1996. Abnormalities in finfish mariculture: an overview of the problem, causes and solutions. In: Chatain, B., Saroglia, M., Sweetman J., and Lavens P. (eds.), Sea Bass and Sea Bream Culture: Problems and Prospects, European Aquaculture Society, Oostende, Belgium, pp. 45- 66.

Divanach, P., Papandroulakis, N., Anastasiasis, P., Kounoundouros, G., Kentouri, M., 1997. Effect of water currents on the development of skeletal deformities in sea bass (Dicentrarchus labrax L.) with functional swimbladder during postlarval and nursery phase. Aquaculture 156, 145-155.

Dupont-Nivet, M., Vandeputte, M., Vergnet, A., Merdy, O., Haffray, P., Chavanne, H., Chatain, B., 2008. Heritabilities and GxE interactions for growth in the European sea bass (Dicentrarchus labrax L.) using a marker-based pedigree. Aquaculture 275, 81-87.

Fauvel, C., Suquet, M., Dreanno, C., Zonno, V., and Menu, B., 1998. Cryopreservation of sea bass (Dicentrarchus labrax) spermatozoa in experimental and production simulating conditions. Aquat. Living Resour. 11, 387-394.

Fjelldal, P.G., Hansen, T.J., Breg, A.E., 2007. A radiological study on the development of vertebral deformities in cultured Atlantic salmon (Salmo salar L.). Aquaculture 273, 721-728.

Fraser, M.R., Anderseon, T.A., De Nys, R., 2004. Ontogenic development of the spine and spinal deformities in larval barramundi (Lates calcarifer) culture. Aquaculture 242, 697-711.

Gavaia, P.J., Dinis, M.T., Cancela, M.L., 2002. Osteological development and abnormalities of the vertebral column and caudal skeleton in larval and juvenile stages of hatchery-reared Senegal sole (Solea senegalensis). Aquaculture 211, 305-323.

Georgakopoulou, E., Angelopoulou, A., Kaspiris, P., Divanach, P., Koumoundouros, G., 2007. Temperature effects on cranial deformities in European sea bass, Dicentrarchus labrax (L.). J. Appl. Ichthyol. 23, 99-103. Gianola, D., Goffinet, B., Bulmer, M.G., 1982. Query: Sire evaluation with best linear unbiased predictors. Biometrics 38, 1085-1088. 
Gilmour, A.R., Gogel, B.J., Cullis, B.R., Welham, S.J., Thompson, R., 2002. ASReml User Guide Release 1.0. VSN International Ltd, Hemel Hepstead, HP1ES, UK.

Gjerde, B., Pante, M.J.R., Baeverfjord, G., 2005. Genetic variation for a vertebral deformity in Atlantic salmon (Salmo salar). Aquaculture 244, 77-87.

Gorman, K.F., Breden, F., 2007. Review: Teleosts as models for human vertebral stability and deformity. Comp. Biochem. Physiol. 145, 28-38.

Kause, A., Ritola, O., Paananen, T., Wahlroos, H., Mäntysaari, E.A., 2005. Genetic trends in growth, sexual maturity and skeletal deformations, and rate of inbreeding in a breeding programme for rainbow trout. Aquaculture 247, 177-187.

Kause, A., Ritola, O., Paananen, T., 2007. Changes in the expression of genetic characteristics across cohorts in skeletal deformations of farmed salmonids. Genet. Select. Evol. 39, 529-543.

Kihara, M., Ogata, S., Kawano, N., Kubota, I., Yamaguchi, R., 2002. Lordosis induction in juvenile red sea bream, Pagrus major, by high swimming activity. Aquaculture 212, 149-158.

Kocour, M., Linhart, O., Vandeputte, M., 2006. Mouth and fin deformities in common carp: is there a genetic basis? Aquacult. Res. 37, 419-422.

Kolstad, K., Thorland, I., Refstie, T., Gjerde, B., 2006a. Body weight, sexual maturity and spinal deformity in strains and families of Atlantic cod (Gadus morhua) at two years of age at different locations along the Norwegian coast. ICES J. Mar. Sci. 63, 246-252.

Kolstad, K., Thorland, I., Refstie, T., Gjerde, B., 2006b. Genetic variation and genotype by location interaction in body weight, spinal deformity and sexual maturity in Atlantic cod (Gadus morhua) reared at different locations off Norway. Aquaculture 259, 66-73.

Komen H., Haffray P., Kaushik S., New M., Olesen I., Liinamo A. E., 2002. Defining breeding goals for the future sustainable aquaculture. World Aquacult., Aquacult. Europe, 11-14.

Kovac, M., Groeneveld, E., 2003. VCE-5 User's Guide and Reference Manual Version 5.1, Institute of Animal Science, Federal Agricultural Research Center, Mariensee, Germany. 68 pp.

Kranenbarg, S., Cleynenbreugel, T.V., Schipper, H., Leeuwen, J.V., 2005a. Adaptive bone formation in acellular vertebrae of sea bass (Dicentrarchus labrax L.). J. Exp. Biol. 208, 34933502.

Kranenbarg, S., Waarsing, J.H., Muller, M., Weinans, H., Leeuwen, J.L.V., 2005b. Lordotic vertebrae in sea bass (Dicentrarchus labrax L.) are adapted to increased loads. J. Biomech. 38, 1239-1246.

Lall, S.P., Lewis-McCrea, L.M., 2007. Role of nutrients in skeletal metabolism and pathology in fish - An overview. Aquaculture 267, 3-19.

Madsen, L., Dalsgaard, I., 1999. Vertebral column deformities in farmed rainbow trout (Oncorhynchus mykiss). Aquaculture 171, 41-48.

McKay, L.R., Gjerde, B., 1986. Genetic variation for a spinal deformity in Atlantic salmon, Salmo salar. Aquaculture 52, 263-272.

Mantysaari, E.A., Quaas, R.L., Grohn, Y.T., 1991. Simulation study on covariance component estimation for two binary traits in an underlying continuous scale. J. Diary Sci. 74, 580-591.

Mercer, J.T., Hill, W.G., 1984. Estimation of genetic parameters for skeletal defects in broiler chikens. Heredity 53, 193-203.

Olausson, A., Ronningen, K., 1975. Estimation of genetic parameters for threshold characters. Acta Agric. Scand., 25, 200-208.

Olivia-Teles, A., Pimentel-Rodrigues, A., 2004. Phosphorus requirement of European sea bass (Dicentrarchus labrax L.) juveniles. Aquacult. Res. 35, 636-642.

Rauw, W.M., Kanis, E., Noordhuizen-Stassen, E.N., Grommers, F.J., 1998. Undesirable side effects of selection for high production efficiency in farm animals: a review. Livest. Prod. Sci. 56, 15-33.

Sfakianakis, D.G., Koumoundouros, G., Divanach, P., Kentouri, M., 2004. Osteological development of the vertebral column and of the fins in Pagellus erythrinus (L. 1758). Temperature effect on the developmental plasticity and morpho-anatomical abnormalities. Aquaculture 232, 407-424.

Sfakianakis, D.G., Georgakopoulou, E., Papadakis, I.E., Divanach, P., Kentouri, M., Koumoundouros, G., 2006. Environmental determinants of haemal lordosis in European sea bass, Dicentrarchus labrax (Linnaeus, 1758). Aquaculture 254, 54-64. 
Sugiura, S.H., Hardy, R.W., Roberts, R.J., 2004. The pathology of phosphorus deficiency in fish a review. J. Fish Dis. 27, 255-265.

Sawada, Y., Hattori, M., Sudo, N., Kato, K., Takagi, Y., Ura, K., Kurata, M., Okada, T., Kumai, H., 2006a. Hypoxic conditions induce centrum defects in red sea bream Pagrus major (Temminck and Schlegel). Aquacult. Res. 37, 805-812.

Sawada, Y., Hattori, M., Iteya, M., Takagi, Y., Ura, K., Seoka, M, Kato, K., Kurata, M., Mitatake, H., Katayama, S., Kumai, H., 2006b. Induction of centrum defects in amberjack Seriola dumerili by exposure of embryos to hypoxia. Fish. Sci. 72, 364-372.

Vandeputte, M., Dupont-Nivet, M., Chatain, B., Chevassus, B., 2001. Setting up a strain testing design for the seabass, Dicentrarchus labrax: a simulation study. Aquaculture 202, 329-342.

Vandeputte, M., Dupont-Nivet, M., Haffray, P., Chavanne, H., Cenadelli, S., Parati, K., Vidal, M.O., Vergnet, A., Chatain, B., 2009. Response to domestication and selection for growth in the European sea bass (Dicentrarchus labrax) in separate and mixed tanks. Aquaculture 286, 20-27.

Villeneuve, L.A.N., Gisbert, E., Moriceau, J., Cahu, C.L., Zambonino Infante, J.L., 2006. Intake of high levels of vitamin $A$ and polyunsaturated fatty acids during different developmental periods modifies the expression of morphogenesis genes in European sea bass (Dicentrarchus labrax). Br. J. Nut. 95, 677-687.

Wagner, E.F., Karsenty, G., 2001. Genetic control of skeletal development. Curr. Opin. Genet. Dev. 11, 527-532.

Witten, P.E., Obach, A., Huysseune, A., Baeverfjord, G., 2006. Vertebrae fusion in Atlantic salmon (Salmo salar): Development, aggravation and pathways of containment. Aquaculture 258, 164172. 


\section{Tables}

Table 1. Number of offspring per family for the analyzed sample of 1328 sea bass.

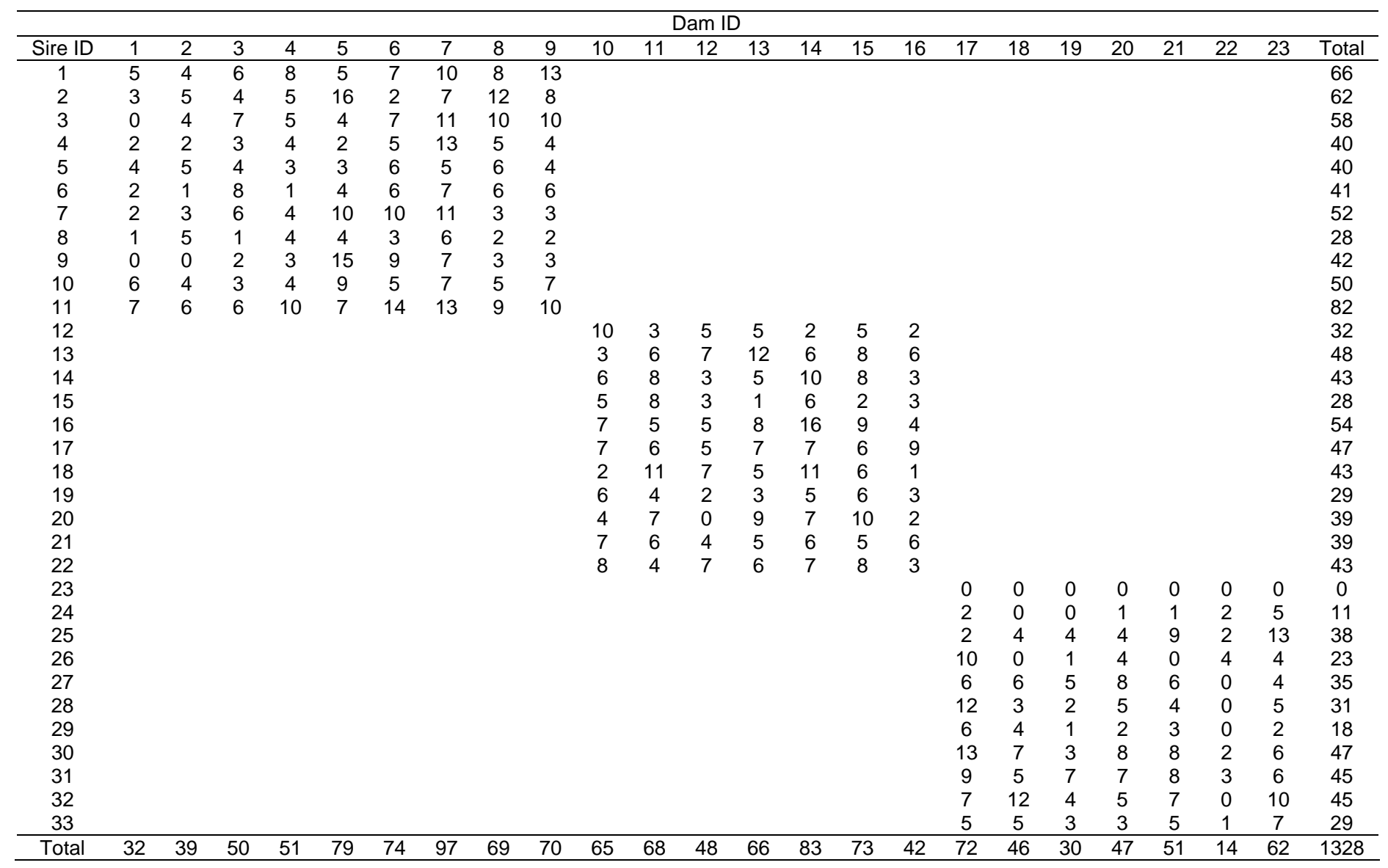


Table 2. Number and proportion of sea bass scored with and without malformation according to two types of measurement and incidence of malformation. Three stages of measurement were realised, i.e. $100 \mathrm{~g}, 400 \mathrm{~g}$ and $800 \mathrm{~g}$. Significance levels of the effects were estimated by logistic regression. Heritability estimates \pm standard errors (SE) from an animal model in VCE on the observed scale $\left(h^{2}{ }^{2}\right)$, and the underlying scale using Dempster and Lerner transformation $\left(h^{2}{ }_{u}\right)$, and from a sire-dam model in ASReml $\left(h^{2}{ }_{\text {ASRem }}\right)$.

\begin{tabular}{|c|c|c|c|c|c|c|c|c|c|c|c|c|}
\hline \multirow{2}{*}{$\begin{array}{c}\text { Record } \\
\text { Stage }\end{array}$} & \multicolumn{9}{|c|}{ External } & \multirow{2}{*}{\multicolumn{3}{|c|}{$\begin{array}{c}\text { Internal } \\
\mathbf{8 0 0 ~ g}\end{array}$}} \\
\hline & & 5. $100 \mathrm{~g}$ & & & $400 \mathrm{~g}$ & & & $800 \mathrm{~g}$ & & & & \\
\hline Deformity & Lordosis & Scoliosis & $\begin{array}{c}\text { 6. Malf } \\
\text { ormatio } \\
n\end{array}$ & Lordosis & Scoliosis & $\begin{array}{c}\text { 7. Malf } \\
\text { ormatio } \\
\mathbf{n}\end{array}$ & Lordosis & Scoliosis & $\begin{array}{c}\text { 8. Malf } \\
\text { ormatio } \\
\mathbf{n}\end{array}$ & Lordosis & Scoliosis & $\begin{array}{c}\text { 9. Malf } \\
\text { ormatio } \\
\mathbf{n}\end{array}$ \\
\hline $\mathrm{N}$ affected & 524 & 70 & 544 & 628 & 103 & 681 & 700 & 408 & 867 & 640 & 975 & 1077 \\
\hline $\begin{array}{l}\text { 10. N } \\
\text { unaffec } \\
\text { ted }\end{array}$ & 804 & 1258 & 784 & 700 & 1225 & 647 & 328 & 920 & 461 & 688 & 353 & 251 \\
\hline $\begin{array}{c}\text { Incidence } \\
\text { (\%) }\end{array}$ & 39 & 5 & 41 & 47 & 8 & 51 & 53 & 31 & 65 & 48 & 73 & 81 \\
\hline Initial tank & 0.0007 & 0.0324 & 0.0008 & 0.0196 & 0.1946 & 0.0230 & 0.0047 & 0.1646 & 0.0659 & 0.0001 & 0.1553 & 0.0337 \\
\hline Sex & 0.0150 & 0.4943 & 0.0158 & 0.0003 & 0.6953 & 0.0020 & 0.0317 & 0.0016 & 0.0240 & 0.2015 & 0.1108 & 0.2688 \\
\hline$h_{0}^{2}$ & $0.19 \pm 0.03$ & $0.06 \pm 0.02$ & $0.19 \pm 0.04$ & $0.19 \pm 0.03$ & $0.07 \pm 0.02$ & $0.20 \pm 0.03$ & $0.17 \pm 0.03$ & $0.11 \pm 0.03$ & $0.15 \pm 0.03$ & $0.21 \pm 0.04$ & $0.07 \pm 0.02$ & $0.10 \pm 0.02$ \\
\hline$h^{2} A S R e m I$ & $0.27 \pm 0.10$ & $0.39 \pm 0.20$ & $0.27 \pm 0.10$ & $0.19 \pm 0.08$ & $0.33 \pm 0.17$ & $0.24 \pm 0.09$ & $0.22 \pm 0.09$ & $0.15 \pm 0.08$ & $0.13 \pm 0.08$ & $0.26 \pm 0.09$ & $0.08 \pm 0.06$ & $0.15 \pm 0.08$ \\
\hline$h^{2} u$ & $0.31 \pm 0.05$ & $0.27 \pm 0.09$ & $0.30 \pm 0.06$ & $0.30 \pm 0.05$ & $0.23 \pm 0.07$ & $0.31 \pm 0.05$ & $0.27 \pm 0.05$ & $0.19 \pm 0.05$ & $0.25 \pm 0.05$ & $0.33 \pm 0.06$ & $0.13 \pm 0.04$ & $0.21 \pm 0.04$ \\
\hline
\end{tabular}


Table 3. Phenotypic (below diagonal) and genetic correlations (above diagonal) between the malformations types for two types of measurement at stage $800 \mathrm{~g}$. Heritabilities on the liability scale \pm standard errors $\left(h^{2} u \pm S E\right)$ are given in bold on the diagonal. N/A: these phenotypic correlations are meaningless as lordosis and scoliosis are included in the malformation trait.

\begin{tabular}{|c|c|c|c|c|c|c|c|}
\hline \multirow{2}{*}{$\begin{array}{c}\text { Record } \\
\text { Deformity }\end{array}$} & & \multicolumn{3}{|c|}{ Internal } & \multicolumn{3}{|c|}{ External } \\
\hline & & $\begin{array}{l}\text { 11. Malfor } \\
\text { mation }\end{array}$ & Lordosis & Scoliosis & $\begin{array}{l}\text { 12. Malfor } \\
\text { mation }\end{array}$ & Lordosis & Scoliosis \\
\hline \multirow{3}{*}{ Internal } & $\begin{array}{l}\text { 13. Malf } \\
\text { ormatio } \\
n\end{array}$ & $0.21 \pm 0.04$ & $0.92(0.05$ & $0.96(0.03$ & $0.96(0.04$ & $0.93(0.05$ & $0.62(012$ \\
\hline & $\begin{array}{l}\text { Lordosi } \\
\text { s }\end{array}$ & $\mathrm{N} / \mathrm{A}$ & $0.33(0.06$ & $0.69(0.10$ & $0.84(0.05$ & $0.99(0.01$ & $0.06(0.15$ \\
\hline & $\begin{array}{l}\text { Scoliosi } \\
\mathrm{s}\end{array}$ & $\mathrm{N} / \mathrm{A}$ & $0.39 \pm 0.04$ & $0.13 \pm 0.04$ & $0.84 \pm 0.08$ & $0.70 \pm 0.10$ & $0.90 \pm 0.10$ \\
\hline \multirow[t]{3}{*}{ External } & $\begin{array}{l}\text { 14. Malf } \\
\text { ormatio } \\
n\end{array}$ & $0.79 \pm 0.03$ & $0.85 \pm 0.02$ & $0.54 \pm 0.04$ & $0.25 \pm 0.05$ & $0.92 \pm 0.03$ & $0.53 \pm 0.11$ \\
\hline & Lordosis & $0.77 \pm 0.03$ & $0.92 \pm 0.01$ & $0.43 \pm 0.04$ & N/A & $0.27 \pm 0.05$ & $0.21 \pm 0.15$ \\
\hline & Scoliosis & $0.46 \pm 0.05$ & $0.19 \pm 0.03$ & $0.45 \pm 0.04$ & N/A & $0.14 \pm 0.04$ & $0.19 \pm 0.05$ \\
\hline
\end{tabular}

Table 4. Phenotypic (below diagonal) and genetic correlations (above diagonal) of lordosis at the different stages. Heritabilities on the liability scale \pm standard errors $\left(\mathrm{h}^{2} \mathrm{u} \pm \mathrm{SE}\right)$ are given in bold on the diagonal.

\begin{tabular}{|c|c|c|c|c|c|}
\hline Record & & & External & & Internal \\
\hline Stage & & $100 \mathrm{~g}$ & $400 \mathrm{~g}$ & $800 \mathrm{~g}$ & $800 \mathrm{~g}$ \\
\hline 15. E & $100 \mathrm{~g}$ & $0.31 \pm 0.05$ & $0.97 \pm 0.02$ & $0.92 \pm 0.03$ & $0.95 \pm 0.02$ \\
\hline xtern & $400 \mathrm{~g}$ & $0.92 \pm 0.01$ & $0.30 \pm 0.05$ & $0.94 \pm 0.02$ & $0.97 \pm 0.02$ \\
\hline al & $800 \mathrm{~g}$ & $0.83 \pm 0.02$ & $0.93 \pm 0.01$ & $0.27 \pm 0.05$ & $0.99 \pm 0.01$ \\
\hline Internal & $800 \mathrm{~g}$ & $0.84 \pm 0.02$ & $0.93 \pm 0.01$ & $0.92 \pm 0.01$ & $0.33 \pm 0.06$ \\
\hline
\end{tabular}


Table 5. Least squares means of fish affected or not by internal deformities at $800 \mathrm{~g}$ for weight $(W)$ and length $(L)$ at all stages adjusted for internal deformities effect; $\underline{P}=$ probability value of the $F$ test for difference between affected and non-affected fish.

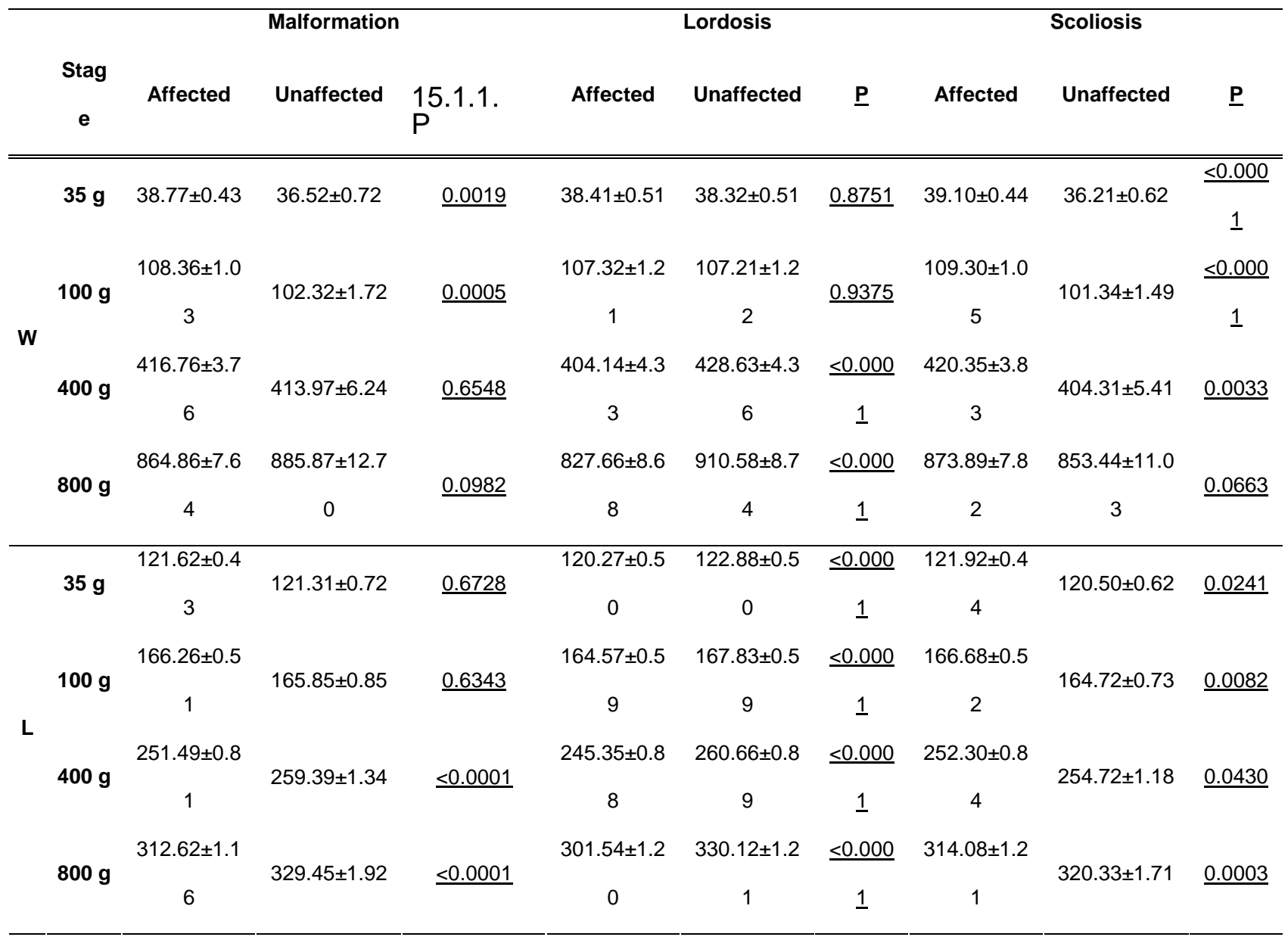

Table 6. Genetic correlations and standard errors between weight, length at different stages and internal deformities at $800 \mathrm{~g}$. N/A : not available due to lack of model convergence.

\begin{tabular}{|c|c|c|c|c|c|c|c|c|}
\hline \multirow[b]{2}{*}{ Stages } & \multicolumn{4}{|c|}{ Weight } & \multicolumn{4}{|c|}{ Length } \\
\hline & $35 \mathrm{~g}$ & $100 \mathrm{~g}$ & $400 \mathrm{~g}$ & $800 \mathrm{~g}$ & $35 \mathrm{~g}$ & $100 \mathrm{~g}$ & $400 \mathrm{~g}$ & $800 \mathrm{~g}$ \\
\hline 16. Malformation & $0.21 \pm 0.15$ & $0.38 \pm 0.15$ & $0.40 \pm 0.14$ & $0.21 \pm 0.16$ & $0.13 \pm 0.14$ & $0.32 \pm 0.16$ & $0.25 \pm 0.15$ & $\begin{array}{c}- \\
0.01 \pm 0.16\end{array}$ \\
\hline S & - & - & - & - & - & - & - & - \\
\hline Lutuosis & $.10 \pm 0.11$ & $.03 \pm 0.12$ & $.08 \pm 0.07$ & $.25 \pm 0.13$ & $0.23 \pm 0.12$ & $0.13 \pm 0.14$ & $0.30 \pm 0.14$ & $0.45 \pm 0.12$ \\
\hline Scoliosis & $0.40 \pm 0.17$ & N/A & $N / A$ & $0.43 \pm 0.21$ & $0.37 \pm 0.19$ & $N / A$ & $N / A$ & $0.19 \pm 0.19$ \\
\hline
\end{tabular}

